\title{
Splenic Manifestation of Prolymphocytic Leukemia
}

National Cancer Institute

\section{Source}

National Cancer Institute. Splenic Manifestation of Prolymphocytic Leukemia. NCI

Thesaurus. Code C7297.

Infiltration and expansion of the white and red pulp of the spleen by prolymphocytic leukemia. 